\title{
JAHN, Joachim, Die Geschichte der Stadt Memmingen: Bd. 1: Von den Anfängen bis zum Ende der Reichsstadt
}

Pierre Monnet

\section{OpenEdition}

\section{Journals}

Édition électronique

URL : http://journals.openedition.org/ifha/1364

DOI : 10.4000/ifha.1364

ISSN : 2198-8943

Éditeur

IFRA - Institut franco-allemand (sciences historiques et sociales)

Référence électronique

Pierre Monnet, «JAHN, Joachim, Die Geschichte der Stadt Memmingen: Bd. 1: Von den Anfängen bis zum Ende der Reichsstadt », Revue de l'IFHA [En ligne], Date de recension, mis en ligne le 01 janvier 1999, consulté le 22 septembre 2020. URL : http://journals.openedition.org/ifha/1364 ; DOI : https://doi.org/ 10.4000/ifha.1364

Ce document a été généré automatiquement le 22 septembre 2020.

(C)IFHA 


\title{
JAHN, Joachim, Die Geschichte der Stadt Memmingen: Bd. 1: Von den Anfängen bis zum Ende der Reichsstadt
}

\author{
Pierre Monnet
}

1 Depuis les travaux de Peter BLICKLE (co-auteur du livre) et les ouvrages de Raimund EIRICH (Memmingens Wirtschaft und Patriziat 1347 bis 1551. Eine wirtschafts- und sozialgeschichtliche Untersuchung über das Memminger Patriziat während der Zunftverfassung, Weißenhorn, 1971) et Peter EITEL (Die oberschwäbischen Reichsstädte im Zeitalter der Zunftherrschaft. Untersuchungen zu ihrer politischen und sozialen Struktur unter besonderer Berücksichtigung der Städte Lindau, Memmingen, Ravensburg und Überlingen, Stuttgart, 1970), la ville souabe de Memmingen attendait une grande et moderne synthèse de son histoire. C'est chose faite, et pas seulement pour le Moyen Âge et la période moderne puisque le second volume est également disponible (Vom Ende der Reichsstadt bis 1945, 1998, 69 DM). Grâce aux meilleurs spécialistes, on citera entre autres Rolf KIESSLING pour la fin du Moyen Âge, Adalbert MISCHLEWSKI pour l'histoire religieuse et Peter BLICKLE pour la Réforme, le lecteur suit le développement topographique, politique, social et religieux de cette cité mentionnée pour la première fois en 1128 (Mammingin) et fondée par le duc guelfe de Bavière à proximité d'une occupation romaine établie sur l'important croisement d'un axe est-ouest entre Salzbourg et la Suisse et nord-sud entre Ulm et les cols alpins. Comme de nombreuses villes de la région tombées aux mains des Staufen à la fin du XIIe s., Memmingen obtient progressivement au XIIIe s. le statut envié de ville immédiate d'Empire, privilège enrichi du droit urbain d'Ulm en 1296. Ces origines guelfes puis staufiennes expliquent la part importante qu'occupa la ministérialité ducale dans la formation du méliorat urbain. Ce méliorat ancien parvint à se maintenir longtemps au pouvoir dans une ville dominée par un patriciat partageant à son avantage les richesses issues du grand commerce méridional entre Allemagne du Sud et Italie du Nord, entre vallée du Rhin et Bavière. La Réforme surgit ici dans une société coupée par les effets d'une polarisation sociale accrue et ébranle un régime politique déjà fragilisé par les assauts des territoires voisins contre son plat pays et contre 
l'organisation de la ligue des villes souabes à laquelle Memmingen appartenait aux XIVe et XVe ss. Au XVIe s., la ville adhéra majoritairement à la nouvelle confession dont elle devint un centre actif, réforma sa constitution qui accorda plus de pouvoir aux métiers. Mais la modification la plus importante intervint peut-être en matière économique: depuis la fin du Moyen Âge, l'organisation des affaires et les axes de circulation des produits ont changé. Memmingen n'est plus dans la situation d'en tirer autant de profit qu'avant. Les chiffres de population traduisent cet essoufflement suivi d'une stagnation de la croissance (aggravée par les effets des guerres du XVIIe s.): de 5 000 habitants environ vers 1500, Memmingen est passée à quelque 4500 vers 1700 . Sur tous ces aspects, sur les hypothèses actuellement en cours pour en rendre compte, sur la culture urbaine avant et après la Réforme, sur les formes complexes de la piété religieuse, cet ouvrage collectif livre plus que des informations. C'est un véritable essai d'explication de différents modèles de développement d'une société urbaine entre prospérité et crises. 